\title{
Sarcoidosis in tuberculosis-endemic regions: India
}

\author{
Kalpana Babu ${ }^{1,2}$
}

\begin{abstract}
Sarcoidosis is a multisystem inflammatory disease of unknown etiology affecting multiple organs. Earlier reports suggested that sarcoidosis was a disease of the developed world. However, recent reports suggest that the disease is found in the developing countries as well. Clinical, radiological, and histopathological similarities with tuberculosis pose a great challenge in countries endemic for tuberculosis. Mantoux test, high resolution computed tomography, and transbronchial lymph node and lung biopsies are diagnostic modalities, which play an important role in the diagnosis of sarcoid. In this review, we look at the epidemiology of sarcoid in tuberculosis-endemic regions, the sarcoidosis-tuberculosis link, clinical profile, diagnostic modalities, dilemma in the diagnosis, and the treatment of this disease.
\end{abstract}

Keywords: Sarcoidosis, Tuberculosis, Ocular involvement, Computed tomography, Mantoux test

\section{Review}

\section{Introduction}

Sarcoidosis is a chronic, multisystem inflammatory disease of unknown etiology characterized by the presence of non-caseating granulomas in different organs. Although the lungs are the most common sites of inflammation, sarcoidosis can involve other organs such as the eyes (intraocular and adnexal), skin, lymph nodes, salivary glands, heart, spleen, liver, and the nervous system [1]. A combination of clinical, radiological, and histological criteria are used to diagnose sarcoidosis. Remarkable clinical similarities with tuberculosis (TB) make the differential diagnosis of the two conditions difficult especially in countries with high burden of tuberculosis. Negative Mantoux test and exclusion of mycobacterial infection or caseation in the biopsy specimens help in diagnosing sarcoidosis. Among the high TB endemic countries, there is increasing literature available on sarcoidosis from India. In this review, we look at the tuberculosis link, epidemiology of sarcoidosis in areas with high TB burden especially India, the emerging literature on sarcoidosis in high TB endemic areas like India, the clinical profile of sarcoidosis including the systemic and ocular features, the diagnostic modalities, and the dilemma faced in the diagnosis and treatment.

\footnotetext{
Correspondence: kalpana@prabhaeyeclinic.com

${ }^{1}$ Vittala International Institute of Ophthalmology, Hosakerehalli, Bangalore, Karnataka 560085, India

${ }^{2}$ Prabha Eye clinic and Research Center, 40th Cross Rd, Jayanagar 8th Block, Bangalore 560070, India
}

Epidemiology of sarcoidosis in areas with high TB burden Sarcoidosis was considered to be a disease seen more commonly in the west and rarely in the developing world in earlier reports. In a study from eight countries of Asia and Africa in 1976, fewer than 30 patients were reported from India, Malaysia, Thailand, Taiwan, and United Arab Emirates, while none from Singapore and Korea [2]. In the recent years, there has been increasing reports from countries like India [3-13], Singapore [14], Malaysia [15], Thailand [16], and Taiwan [17]. In all probabilities, the disease was probably overshadowed by the presence of tuberculosis. Reports have also mentioned that the increase in incidence of sarcoidosis was probably related to the decrease in infectious diseases, especially tuberculosis and the implementation of tuberculosis control programs [4]. However, the cases of tuberculosis are still prevalent in the developing world, but we diagnose sarcoidosis with greater frequency in recent times. Unlike in the past, this is probably due to the increased awareness of the disease and improved efforts to make a diagnosis. The availability of computed tomography and fiberoptic bronchoscopy for transbronchial lung and lymph node biopsies has made a big difference in the diagnosis of the disease [12].

The true burden of sarcoidosis in India is not clearly known, as reliable epidemiological data are not available. It has been estimated that sarcoidosis constituted 10 to 12 cases per 1,000 new registrations in a respiratory unit at Kolkata and 61.2/100,000 new cases at a center in

\section{包 Springer}

(c) 2013 Babu; licensee Springer. This is an Open Access article distributed under the terms of the Creative Commons Attribution License (http://creativecommons.org/licenses/by/2.0), which permits unrestricted use, distribution, and reproduction in any medium, provided the original work is properly cited. 
New Delhi in a report published in 2002 [13]. The cases of sarcoidosis have been reported across the country with no data on regional or ethnic differences and are now considered routinely in the differential diagnosis of respiratory and non-respiratory diseases including ocular problems. Reports of ocular sarcoid have been reported from across the country in the recent years [8-10,18-22].

\section{The tuberculosis link}

Mycobacterium tuberculosis as a cause of sarcoidosis has been extensively studied in the literature [23-25]. Reports of previous history of contact with tuberculosis in patients with sarcoidosis [26], similarities in time trends in the prevalence of the two diseases, and ethnic populations with higher incidence of TB having high incidence of sarcoidosis are described in the literature [27,28]. Studies from India reporting patients with TB preceding the development of sarcoidosis or concurrent presence of both diseases have been described [3,4]. Molecular techniques such as nucleic acid amplification tests have demonstrated mycobacterial DNA and RNA in 30\% of sarcoid biopsy tissues $[5,25]$. This was $48 \%$ in a prospective study from India [5]. Mycobacterial proteins like MTb catalase peroxidase (mKatG), superoxide dismutase, mycolyl transferase, and heat shock proteins have been detected [29]; immune responses to them have also been detected in sarcoid tissues, blood, and bronchoalveolar lavage fluid. When interferon-gamma (IFN- $\gamma$ ) ELISPOT assays and flow cytometry were used to assess the lung and blood T-cell responses to $\mathrm{mKatG}$ in sarcoidosis patients, a higher frequency of mKatG-reactive, IFN- $\gamma$ expressing $\mathrm{T}$ cells was demonstrated in patients with active sarcoidosis than in controls [30-33]. This antigen also elicited granulomatous response in animal models, renewing interest in mycobacteria as a causative agent in sarcoidosis. Studies from India have shown positivity to QuantiFERON TB gold test in a small subset of sarcoid patients [6].

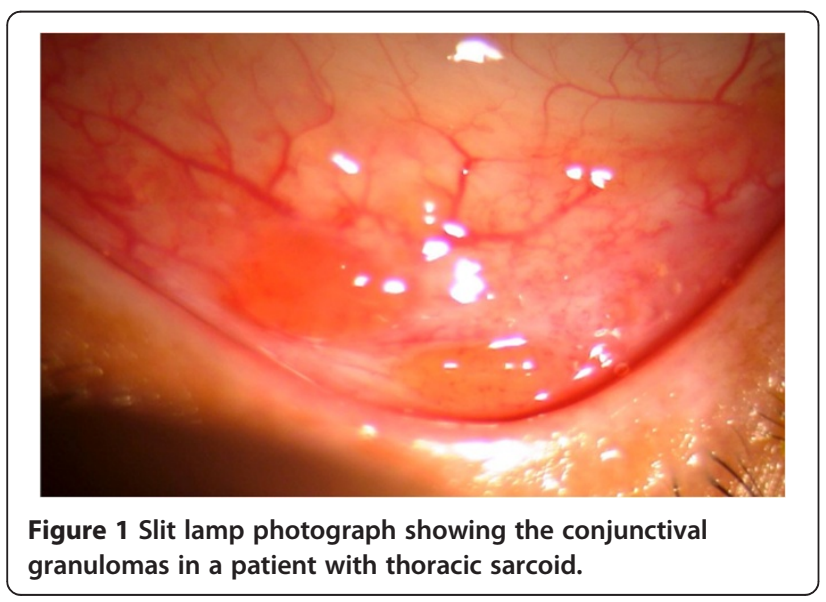

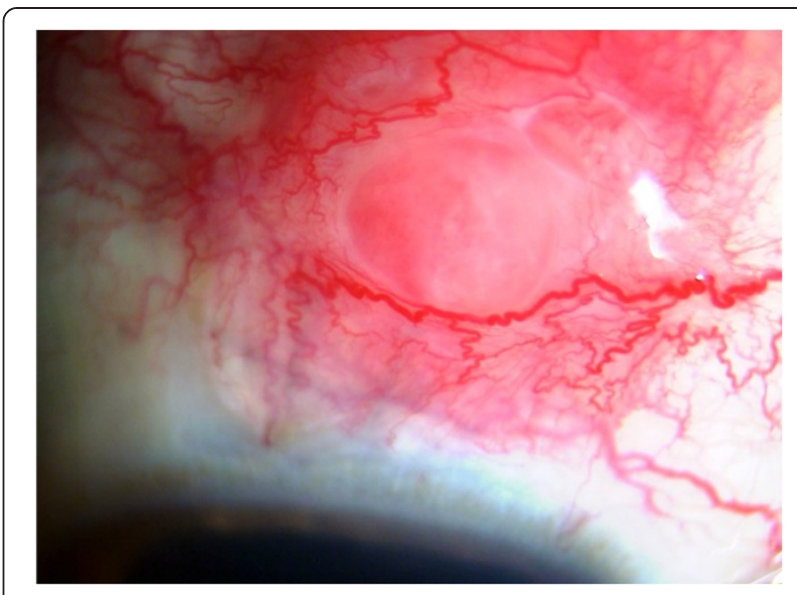

Figure 2 Slit lamp photograph showing the scleral nodule in a patient with sarcoidosis.

\section{Systemic sarcoidosis: clinical features}

The course of sarcoidosis ranges from asymptomatic to severe disease. Male preponderance with a mean age of 40 years is reported in most Indian reports $[3,4,7,10]$. Reports in ophthalmology literature from south India have shown a female preponderance [9].

The disease affects predominantly the lungs, thoracic lymph nodes, skin, and eyes. Clinically, patients may be asymptomatic or complain of cough or breathlessness. Constitutional symptoms such as fever, malaise, fatigue, and weight loss may be present. The most frequent intrathoracic involvement is the presence of hilar or mediastinal lymph node enlargements with or without radiologic evidence of interstitial involvement in one-third of patients. The miliary pattern can be seen in sarcoidosis and may be misdiagnosed and treated for tuberculosis [3]. High resolution computed tomography $(\mathrm{CT})$ is more diagnostic than chest X-ray $[3,4,22]$.

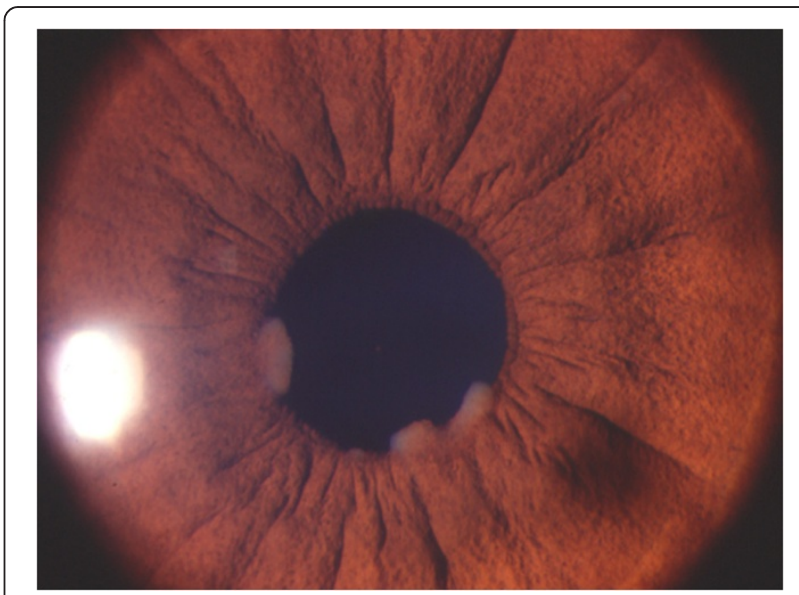

Figure 3 Slit lamp photograph showing the granulomatous anterior uveitis with large Koeppe nodules. 


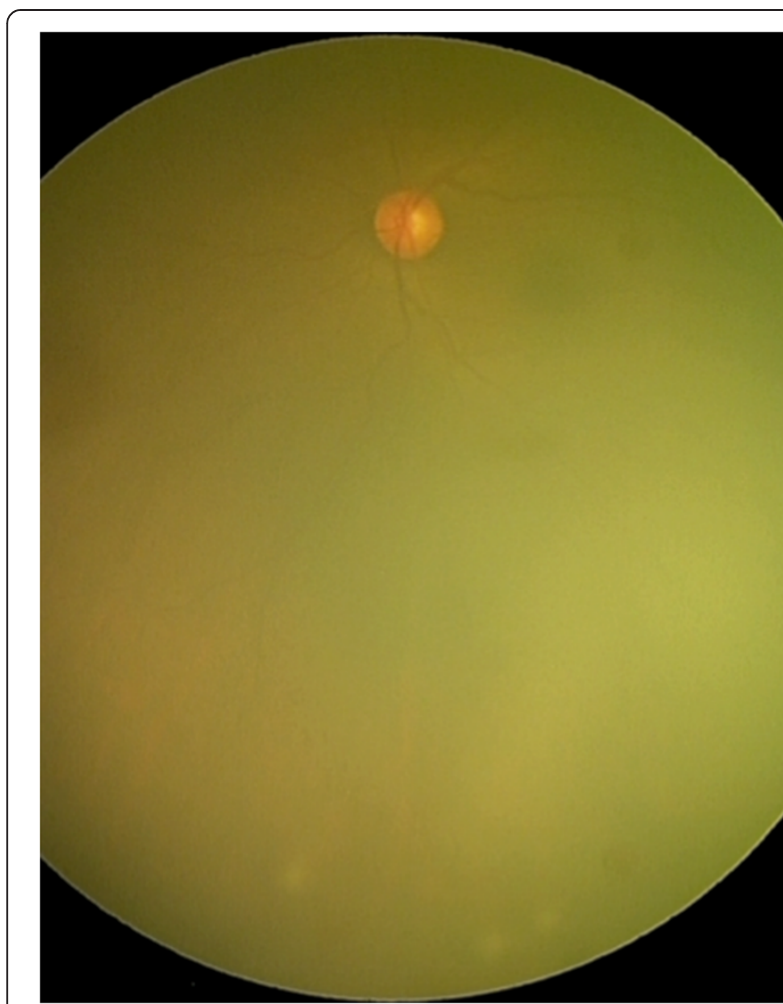

Figure 4 Fundus photograph showing vitritis with snow ball opacities in the peripheral retina.

Skin involvement may include sarcoid granulomas and erythema nodosum. Bilateral parotid gland enlargement, hepatic involvement with granulomas, renal insufficiency, myocardial involvement with heart failure, hypertension and conduction abnormalities, arthropathy, neurological involvement in the form of recurrent laryngeal nerve palsy, Bells' palsy, other cranial neuropathies and spinal chord involvement, generalized lymphadenopathy, and minor hematologic abnormalities have been

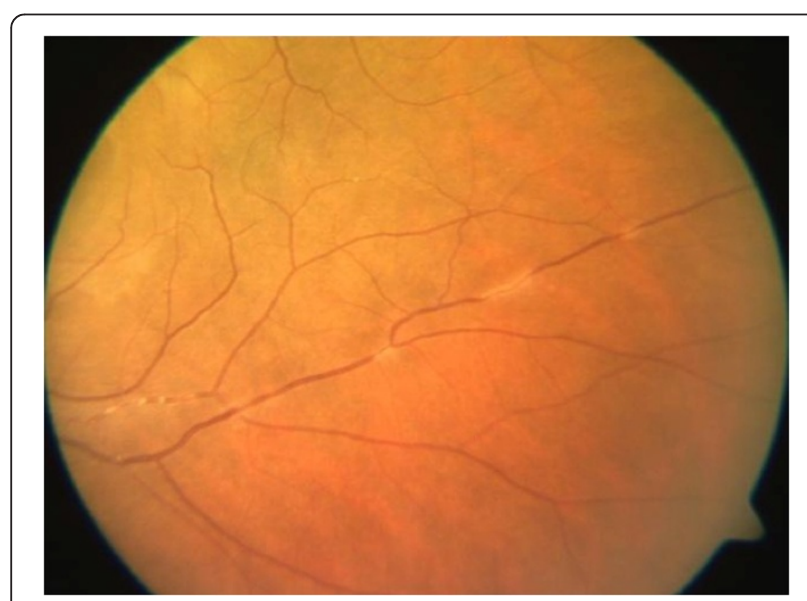

Figure 5 Fundus photograph showing the perivasculitis.

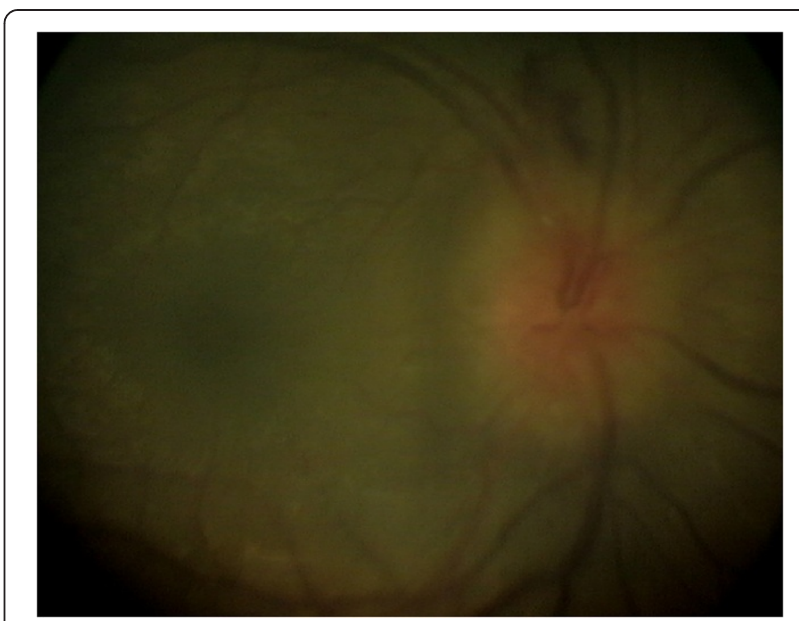

Figure 6 Fundus photograph showing the disc edema.

reported from India [3,4]. Sporadic reports of childhood sarcoidosis are seen in India. Those cases manifesting with generalized lymphadenopathy are mistaken for TB and are usually treated initially with antitubercular therapy [3].

\section{Ocular sarcoidosis: clinical features}

Patients may present directly to an ophthalmology clinic with blurred vision, floaters, redness or discomfort, or may be referred by the pulmonologists or rheumatologists for an ocular evaluation. Ocular disease may be the initial manifestation in sarcoidosis. Ocular involvement occurs in $25 \%$ to $60 \%$ of patients with systemic sarcoidosis presenting to a respiratory center [10]. This was around $95 \%$ in those who presented to the tertiary eye care center probably due to the referral bias [9]. Ocular manifestations include uveitis, dry eye, conjunctival

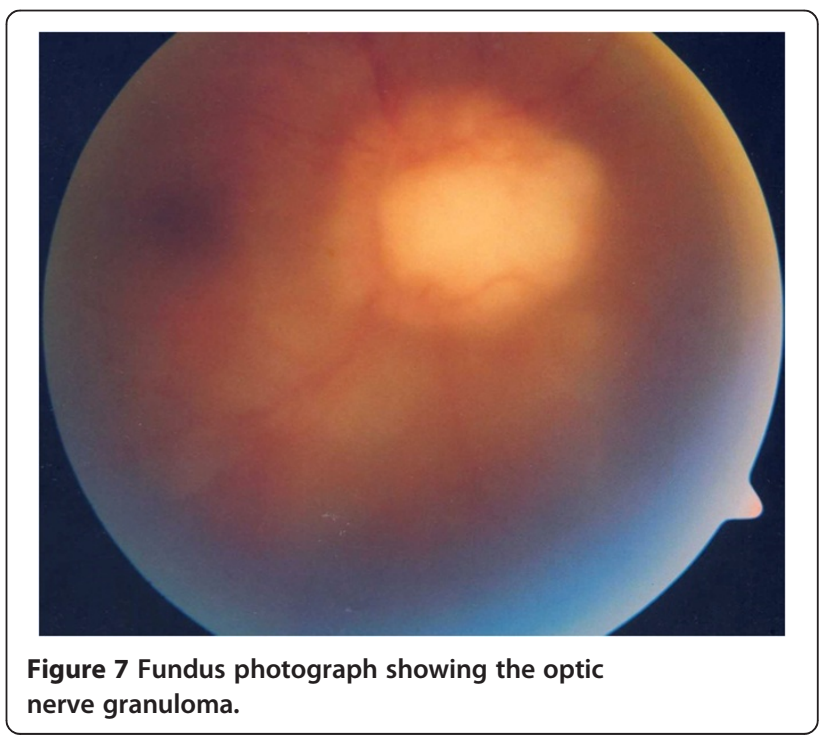




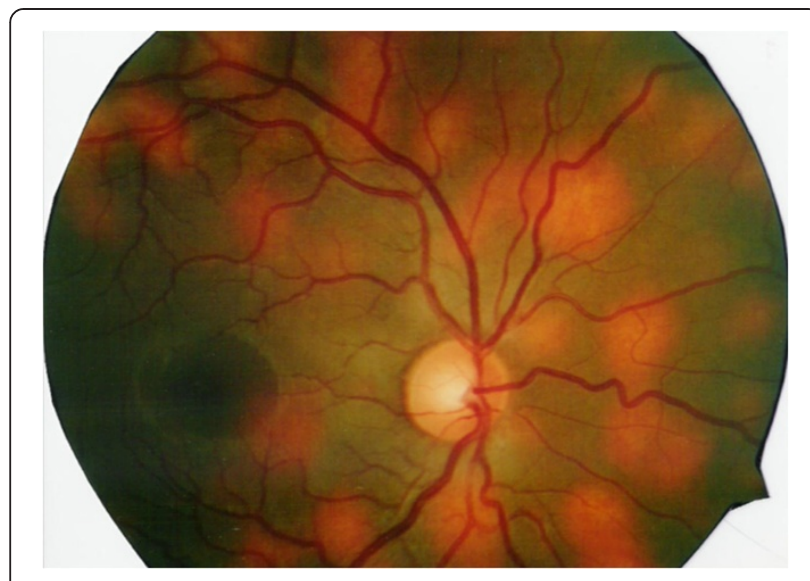

Figure 8 Fundus photograph showing the choroidal granulomas.

granulomas, and involvement of the orbit and optic nerve $[9,10,18-21,34]$.

In contrast to reports from western literature [35], panuveitis is the most common manifestation seen in most of the reports from India. As most of the reports are from tertiary referral centers, it could be possible that initial presentations of anterior uveitis could be treated by general ophthalmologists prior to referral.

Anterior uveitis could be acute iridocyclitis or a chronic granulomatous uveitis with keratic precipitates, which may vary from cellular to large mutton fat type of keratic precipitates. Iris nodules such as the Koeppe and busacca nodules and iris granulomas may be seen. Granulomas may also be seen in the trabecular meshwork causing increase in intraocular pressure at the time of activity. Intermediate uveitis with vitritis, peripheral vasculitis, snowball opacities, and snow banking have been described in reports from India as well. Posterior

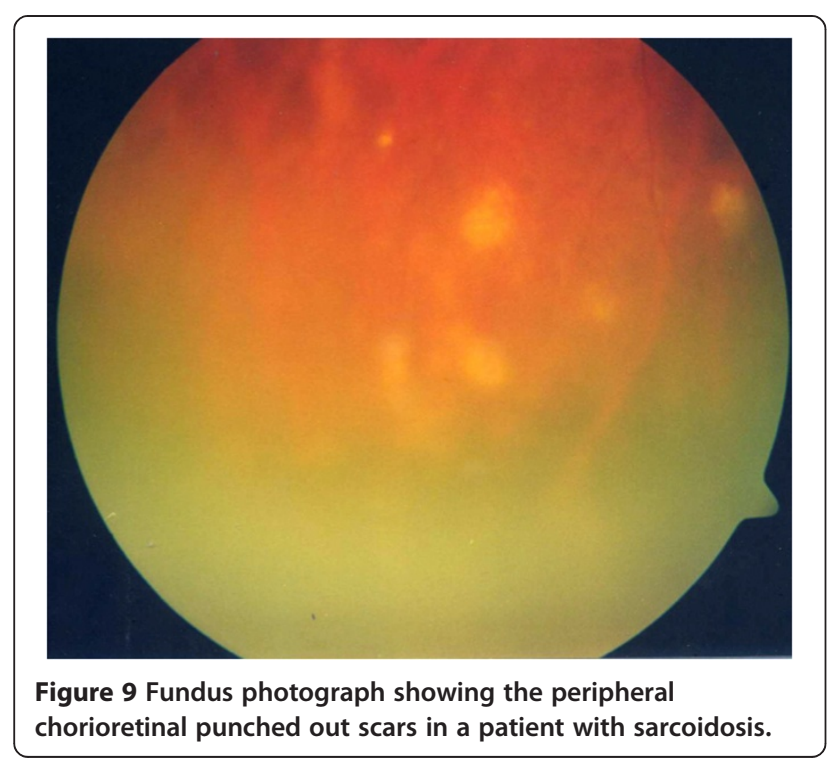

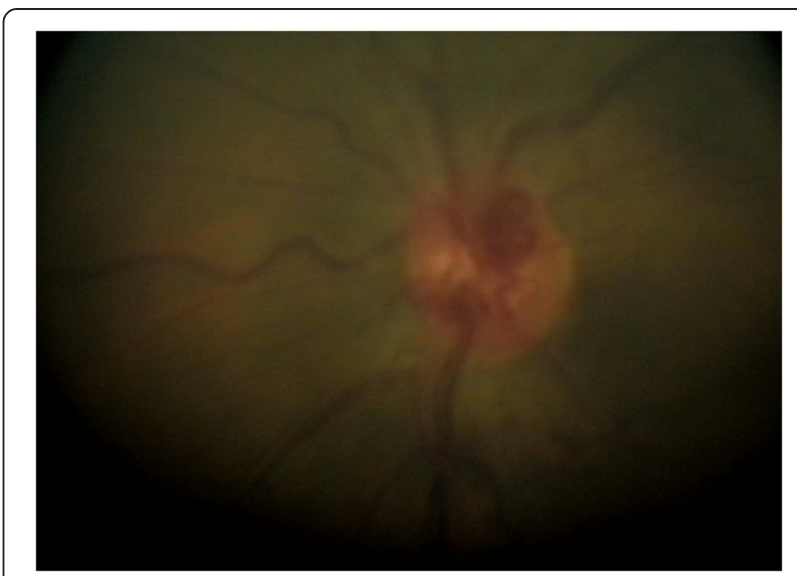

Figure 10 Fundus photograph showing the optic nerve head anastomosis in a patient with cutaneous sarcoidosis.

segment involvement includes periphlebitis with characteristic 'candle wax dripping appearances', multifocal chorioretinitis, peripheral punched out chorioretinal lesions, choroid and optic nerve granulomas, optic disc edema, papilledema, optociliary shunts, and arterial macro aneurysms. Rare manifestations of scleral nodule, vasoproliferative tumors, and retinitis have also been reported from India. Conjunctival granulomas, bilateral lacrimal gland enlargement, and orbital mass lesions have been reported from India $[9,34]$. Illustrations are provided as Figures 1, 2, 3, 4, 5, 6, 7 ,8 ,9, 10, 11, 12, 13, 14 , and 15.

\section{Diagnostic modalities}

A negative Mantoux (PPD) skin test is considered to suggest sarcoidosis and is usually seen in $90 \%$ of sarcoid

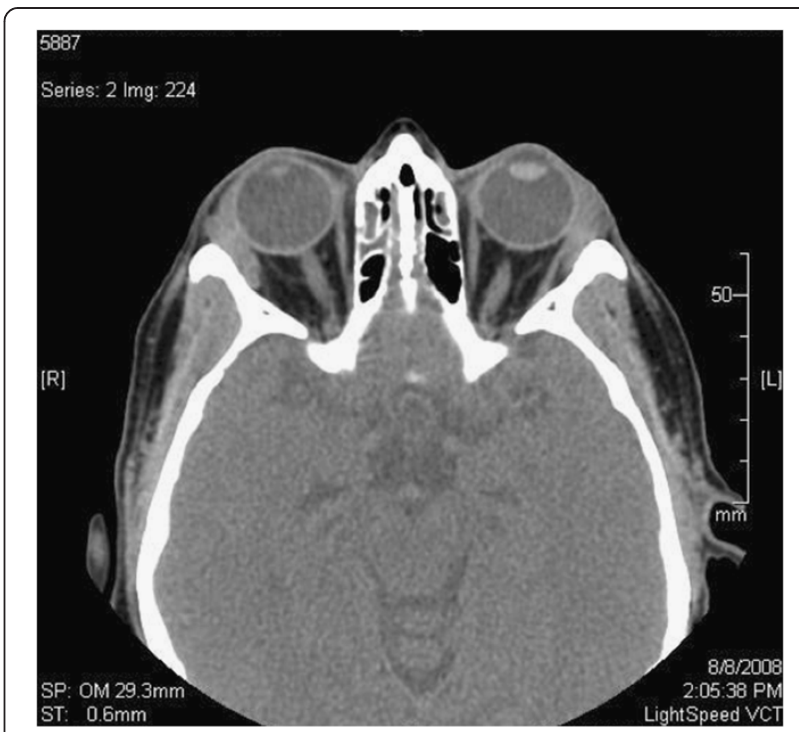

Figure 11 High resolution computed tomography of the orbits showing bilateral lacrimal gland enlargement. 


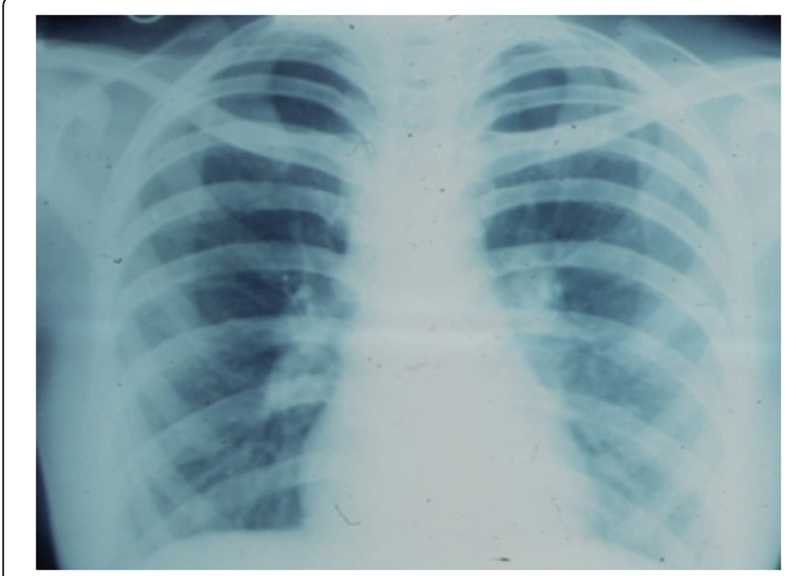

Figure 12 Chest X-ray showing bilateral hilar lymphadenopathy in a patient with sarcoidosis.

patients [36]. Elevated serum angiotensin converting enzyme is elevated in only half the patients with sarcoidosis and may be also seen in tuberculosis and, hence, nonspecific. Bronchoalveolar lavage and gallium citrate scanning is also nonspecific and may be positive in tuberculosis as well.

High resolution CT is of great help in making the diagnosis of sarcoidosis by detecting interstitial involvement and lymphadenopathy. Contrast-enhanced CT may help distinguish sarcoid from tubercular lymph node enlargement, which would usually show a central hypodensity corresponding to the caseation and peripheral contrast enhancement. The frequent use of fiberoptic

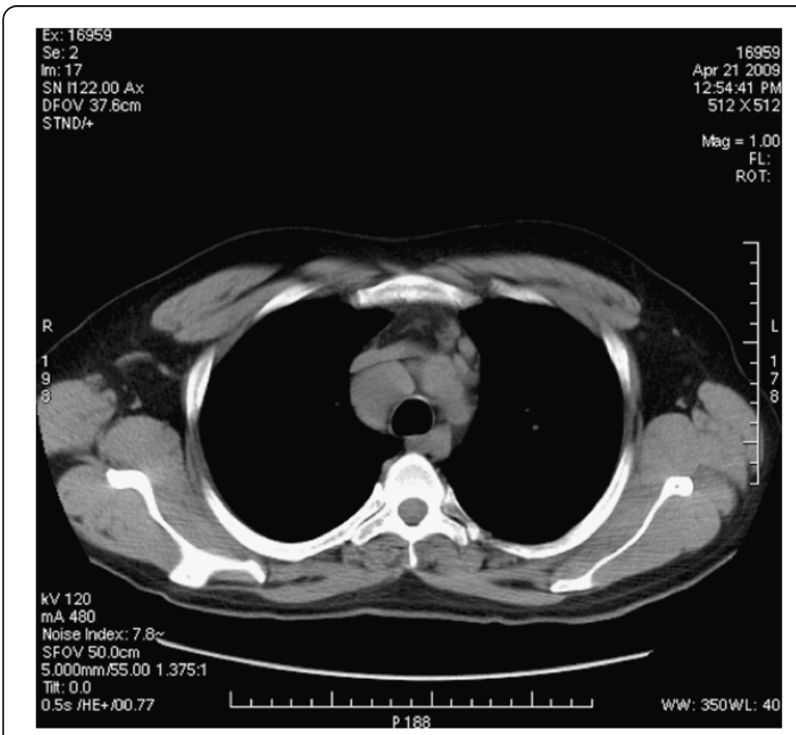

Figure 13 High resolution computed tomography of the thorax showing mediastinal lymphadenopathy in a patient with grade 2 sarcoid with respiratory symptoms.

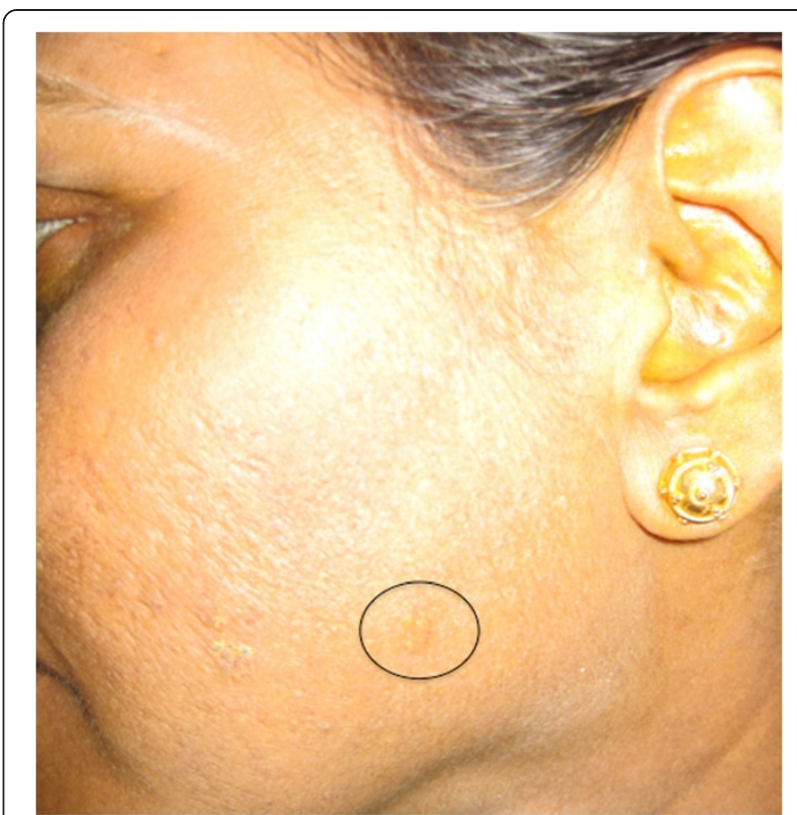

Figure 14 External photograph of sarcoid granuloma on the face.

bronchoscopy with transbronchial lymph node and endobronchial lung biopsies with diagnostic yield of about $80 \%$ have helped in the recognition of sarcoidosis. Microbiology (smear and culture for MTB) and histopathology are routinely done on the aspirates/biopsy material to rule out TB.

\section{The sarcoid-TB dilemma}

Both TB and sarcoid share remarkable similarities in their clinical and radiological presentations. Both diseases present with constitutional symptoms of fever, malaise, weight loss, and fatigue. Respiratory symptoms are common to both diseases. Similar ocular manifestations are

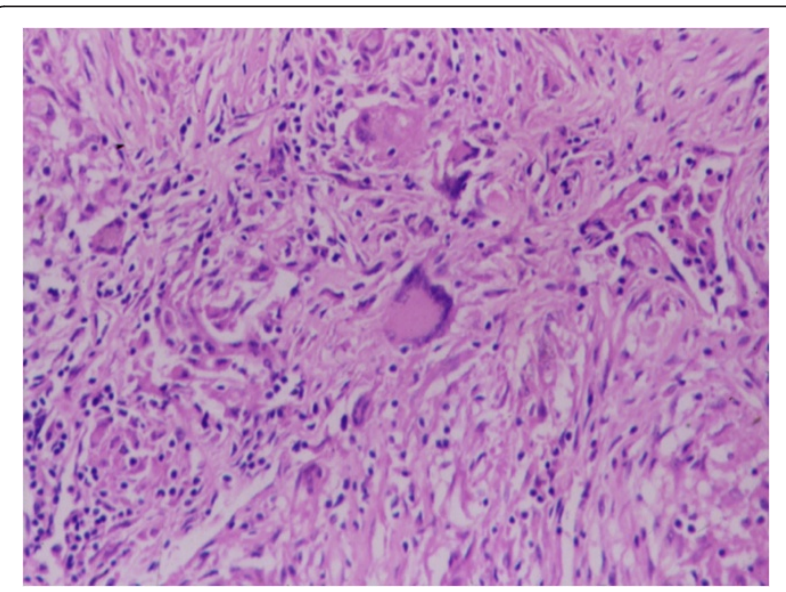

Figure 15 Photomicrograph of biopsy from lacrimal glands showing non-caseating granulomas with giant cells. 
seen in both diseases. Serpiginous-like choroiditis in the Indian subcontinent are more likely to be associated with tuberculosis [37]; however, rare case reports of sarcoidosis presenting with an APMPPE-like manifestation have also been reported [35]. Dry eye, bilateral lacrimal gland enlargements are more common in sarcoidosis, though latter have been reported in TB also [38]. In a study conducted by us in patients with biopsy-proven granulomatous uveitis, we reported that the likelihood ratio of the uveitis being tubercular is around $76.6 \%$, if a combination of pigmented multifocal choroiditis patches along the retinal blood vessels, a Schirmer test $\geq 10 \mathrm{~mm}$, and a positive Mantoux test are present [8].

Radiologic similarities may be seen in both diseases. Discrete, bilateral, symmetrical lymph node enlargement is usually seen in sarcoidosis. Fibrosis and military distribution although common in TB may be seen in both diseases. Both diseases show granulomatous inflammation on histopathology. Caseation is seen in tuberculosis. Fibrinoid necrosis though rare can occur in up to $30 \%$ of cases of sarcoidosis. There are no specific features enough to differentiate the two conditions with certainty, except a positive culture of MTb. A positive PCR for MTb may be seen in the biopsy samples of sarcoidosis.

Differentiating the two conditions pose a challenge, particularly in countries with high prevalence of TB. A combination of clinical, radiologic, and laboratory tests are used to make a diagnosis of sarcoidosis. Tuberculin skin test plays an important role in the diagnosis [36]. Tuberculin anergy is a clinically important phenomenon in sarcoidosis. As a negative tuberculin test excludes TB except in immunosuppressed or extremely sick individuals, we do attach a great deal of importance to this test. On the other hand, patients with positive interferon- $\gamma$ release assays (IGRA) are sometimes misdiagnosed as TB. A recent study from India shows positive interferon- $\gamma$ release assay in some patients with sarcoidosis. Thus, in countries with high TB burden, one must not make a diagnosis of $\mathrm{TB}$ on the basis of positive IGRA alone [6].

\section{Treatment}

Corticosteroids are the mainstay of treatment in sarcoidosis. In chronic cases or in those patients were steroids are contraindicated, immunosuppressants like methotrexate, azathioprine, mycophenolate mofetil, cyclosporine, and cyclophosphamide have been used [39,40]. Methotrexate has been used most frequently, as it is cost effective. Aggressive cases may even require intravenous methyl prednisolone or pulse intravenous cyclophosphamide. Use of biologics like rituximab [41] in steroidresistant cases of sarcoid has been reported. Many times, patients are treated with antitubercular therapy prior to the diagnosis of sarcoid.

\section{Conclusions}

Diagnosing sarcoid in countries with high TB burden does pose a significant challenge. However, new cases of sarcoid are increasingly diagnosed in TB endemic areas in recent years due to increased awareness and better availability of diagnostic modalities. Ocular evaluations do contribute in making a diagnosis of systemic sarcoid. Negative Mantoux test is still being considered an important diagnostic test to make a diagnosis. Sarcoidosis does exist in populations with high TB burden, and the association between sarcoid and TB continues to be an enigma. Prospective studies from the Indian continent on the epidemiological data, genotypic and phenotypic variations, and the role of mycobacteria in the development of sarcoidosis would contribute a great deal in understanding this disease.

\section{Consent}

Written informed consent was obtained from the patient for the publication of this report and any accompanying images. The consent to publish has been provided by the patient with the face photograph and has been approved by our Institutional Review Board (Vittala International Institute of Ophthalmology).

\section{Competing interest}

The author declares that she has no competing interests.

Received: 8 May 2013 Accepted: 19 June 2013

Published: 27 June 2013

\section{References}

1. Newman LS, Rose CS, Maier LA (1997) Sarcoidosis. N Engl J Med 336:1223-1234

2. Hosoda Y, Kosuda T, Yamamoto M, Hongo O, Mochizumi H, Mikami R, Homma H, Fujita S, Ohira I, Izumi T, Kobara Y, Yammato H, Oshima S, Teramatsu T, Maekawa N, Tsuji S, Soon CP, Sodhy TS, Bovornkitti S,

Chakravarty SC, Yang SP, Gomaa T (1976) A cooperative study of sarcoidosis in Asia and Africa: descriptive epidemiology. Ann N Y Acad Sci 278:347-354

3. Jindal SK, Gupta D, Aggarwal AN (2000) Sarcoidosis in developing countries. Curr Opin Pulm Med 6(5):448-454

4. Gupta D, Agarwal R, Aggarwal AN, Jindal SK (2012) Sarcoidosis and tuberculosis: the same disease with different manifestations or similar manifestations of different disorders. Curr Opin Pulm Med 18(5):506-516

5. Gupta D, Agarwal R, Aggarwal N, Jindal SK (2007) Molecular evidence for the role of mycobacteria in sarcoidosis: a meta analysis. Eur Respir J 30:508-516

6. Gupta D, Kumar S, Aggarwal AN, Verma I, Agarwal R (2011) Interferon gamma release assay (QuantiFERON-TB Gold In Tube) in patients of sarcoidosis from a population with high prevalence of tuberculosis infection. Sarcoidosis Vasc Diffuse Lung Dis 28(2):95-101

7. Kumar R, Goel N, Gaur SN (2012) Sarcoidosis in north Indian population: a retrospective study. Indian J Chest Dis Allied Sci 54(2):99-104

8. Babu K, Kini R, Mehta R, Philips M, Subbakrishna DK, Murthy KR (2012) Predictors for tubercular uveitis: a comparison between biopsy-proven cases of tubercular and sarcoid uveitis. Retina 32(5):1017-1020

9. Babu K, Kini R, Mehta R, Abraham MP, Subbakrishna DK, Murthy KR (2010) Clinical profile of ocular sarcoidosis in a South Indian patient population. Ocul Immunol Inflamm 18(5):362-369

10. Khanna A, Sidhu U, Bajwa G, Malhotra V (2007) Pattern of ocular manifestations in patients with sarcoidosis in developing countries. Acta Ophthalmol Scand 85(6):609-612

11. Mootha VK, Agarwal R, Aggarwal AN, Gupta D, Ahmed J, Verma I, Bal A (2010) The sarcoid-tuberculosis link: evidence from a high TB prevalence country. J Infect 60(6):501-503 
12. Agarwal R, Aggarwal AN, Gupta D (2012) Efficacy and safety of conventional TBNA in sarcoidosis: a systematic review and meta-analysis. Respir Care. in press

13. Sharma SK, Mohan A (2004) Sarcoidosis in India: not so rare. J Indian Acad Clin Med 5(1):12-21

14. Anantham D, Ong SJ, Chuah KL, Fook-Chong S, Hsu A, Eng P (2007) Sarcoidosis in Singapore: epidemiology, clinical presentation and ethnic differences. Respirology 12(3):355-360

15. Liam CK, Menon A (1993) Sarcoidosis: a review of cases seen at the university hospital, Kuala Lumpur. Singapore Med J 34(2):153-156

16. Pathanapitoon $\mathrm{K}$, Goossens $\mathrm{JH}$, van Tilborg TC, Kunavisarut $\mathrm{P}$, Choovuthayakorn J, Rothova A (2010) Ocular sarcoidosis in Thailand. Eye (Lond) 24(11):1669-1674

17. Sheu SJ, Chang FP, Wu TT, Chuang CT (2010) Ocular sarcoidosis in southern Taiwan. Ocul Immunol Inflamm 18(3):152-157

18. Babu K, Kini R, Mehta R (2010) Scleral nodule and bilateral disc edema as a presenting manifestation of systemic sarcoidosis. Ocul Immunol Inflamm 18 (3):158-161

19. Biswas J, Krishnakumar S, Raghavendran R, Mahesh L (2000) Lid swelling and diplopia as presenting features of orbital sarcoid. Indian J Ophthalmol 48(3):231-233

20. Shabbir Shafiq J, Biswas I (2008) Optic nerve head sarcoid granuloma treated with intravenous methyl prednisolone. Oman J Ophthalmol 1(1):28-31

21. Verma A, Biswas J (2010) Choroidal granuloma as an initial manifestation of systemic sarcoidosis. Int Ophthalmol 30(5):603-606

22. Ganesh SK, Roopleen BJ, Veena N (2011) Role of high-resolution computerized tomography (HRCT) of the chest in granulomatous uveitis: a tertiary uveitis clinic experience from India. Ocul Immunol Inflamm 19(1):51-57

23. Brownell I, Ramirez-Valle F, Sanchez M, Prystowsky S (2011) Evidence for mycobacteria in sarcoidosis. Am J Respir Cell Mol Biol 45:899-905

24. Scadding JG (1960) Mycobacterium tuberculosis in the aetiology of sarcoidosis. Br Med J 2:1617-1623

25. Drake WP, Newman LS (2006) Mycobacterial antigens may be important in sarcoidosis pathogenesis. Curr Opin Pulm Med 12:359-363

26. Parsons V (1960) Awareness of family and contact history of tuberculosis in generalized sarcoidosis. Br Med J 2:1756-1759

27. Hosoda Y, Sasagawa S, Yamaguchi T (2004) Sarcoidosis and tuberculosis: epidemiological similarities and dissimilarities. A review of a series of studies in a Japanese work population (1941-1996) and the general population (1959-1984). Sarcoidosis Vasc Diffuse Lung Dis 21(2):85-93

28. Hosoda Y, Yamaguchi M, Hiraga Y (1997) Global epidemiology of sarcoidosis. What story do prevalence and incidence tell us? Clin Chest Med 18(4):681-694

29. Drake WP, Newman LS (2006) Mycobacterial antigens may be important in sarcoidosis pathogenesis. Curr Opin Pulm Med 12(5):359-363

30. Agarwal R, Gupta D, Srinivas R, Verma I, Aggarwal AN, Laal S (2012) Analysis of humoral responses to proteins encoded by region of difference 1 of mycobacterium tuberculosis in sarcoidosis in a high tuberculosis prevalence country. Indian J Med Res 135(6):920-923

31. Chan AS, Sharma OP, Rao NA (2010) Review for disease of the year: immunopathogenesis of ocular sarcoidosis. Ocul Immunol Inflamm 18 (3):143-151

32. Song Z, Marzilli L, Greenlee BM, Chen ES, Silver RF, Askin FB, Teirstein AS, Zhang Y, Cotter RJ, Moller DR (2005) Mycobacterial catalase-peroxidase is a tissue antigen and target of the adaptive immune response in systemic sarcoidosis. J Exp Med 201(5):755-767. Erratum in: J Exp Med. 2005; 202(5):721

33. Chen ES, Wahlström J, Song Z, Willett MH, Wikén M, Yung RC, West EE, McDyer JF, Zhang Y, Eklund A, Grunewald J, Moller DR (2008) T cell responses to mycobacterial catalase-peroxidase profile a pathogenic antigen in systemic sarcoidosis. J Immunol 181(12):8784-8796

34. Kim UR, Khazaei H, Stewart WB, Shah AD (2010) Spectrum of orbital disease in South India: an Aravind study of 6328 consecutive patients. Ophthal Plast Reconst Surg 26(5):315-322

35. Rothova A (2000) Ocular involvement in sarcoidosis. Br J Ophthalmol 84 (1):110-116

36. Smith-Rohrberg D, Sharma SK (2006) Tuberculin skin test among pulmonary sarcoidosis patients with and without tuberculosis: its utility for the screening of the two conditions in tuberculosis-endemic regions. Sarcoidosis Vasc Diffuse Lung Dis 23(2):130-134

37. Bansal R, Gupta A, Gupta V, Dogra MR, Sharma A, Bambery P (2012) Tubercular serpiginous-like choroiditis presenting as multifocal serpiginoid choroiditis. Ophthalmology 119(11):2334-2342
38. Bansal RK, Malhotra C, Bhatia R, Chhabra S, Sood S (2006) Tubercular dacryoadenitis-a case report and review of literature. Indian J Pathol Microbiol 49(3):385-387

39. Baughman RP, Lower EE, Ingledue R, Kaufman AH (2012) Management of ocular sarcoidosis. Sarcoidosis Vasc Diffuse Lung Dis 29(1):26-33

40. Bhat P, Cervantes-Castañeda RA, Doctor PP, Anzaar F, Foster CS (2009) Mycophenolate mofetil therapy for sarcoidosis-associated uveitis. Ocul Immunol Inflamm 17(3):185-190

41. Lower EE, Baughman RP, Kaufman AH (2012) Rituximab for refractory granulomatous eye disease. Clin Ophthalmol 6:1613-1618

doi:10.1186/1869-5760-3-53

Cite this article as: Babu: Sarcoidosis in tuberculosis-endemic regions: India. Journal of Ophthalmic Inflammation and Infection 2013 3:53.

\section{Submit your manuscript to a SpringerOpen ${ }^{\odot}$ journal and benefit from:}

- Convenient online submission

- Rigorous peer review

- Immediate publication on acceptance

- Open access: articles freely available online

- High visibility within the field

- Retaining the copyright to your article

Submit your next manuscript at $\gg$ springeropen.com 